
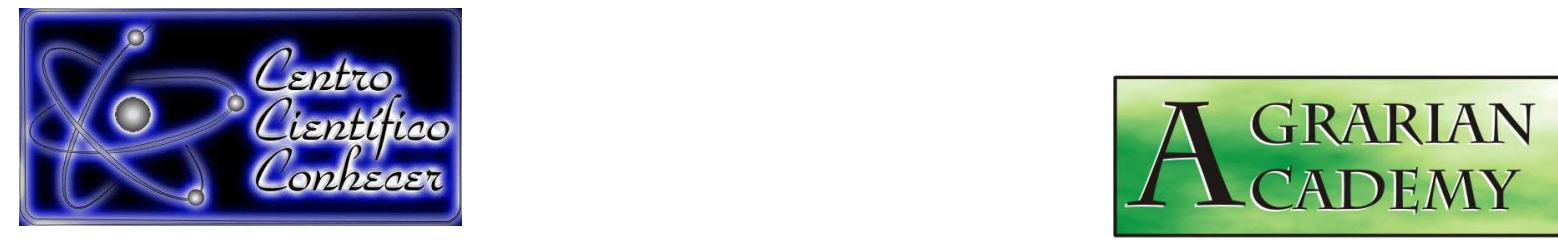

\title{
EMERGÊNCIA DE VARIEDADES DE ALFACE SUBMETIDAS A DIFERENTES PERÍODOS DE LUMINOSIDADE SOLAR DIRETA
}

Lays Laianny Amaro Bezerra ${ }^{1}$, Pedro Vinícius Patrício Silva², Ítalo Bruno Bezerra Mota $^{2}$, Felipe Thomaz da Camara ${ }^{3}$

1 Graduanda em Agronomia da Universidade Federal do Cariri (layslaianny@hotmail.com) Crato-CE, Brasil;

2 Graduando em Agronomia da Universidade Federal do Cariri;

3 Doutor em Agronomia. Docente do curso de Agronomia da Universidade Federal do Cariri.

Recebido em: 15/04/2017 - Aprovado em: 22/07/2017 - Publicado em: 31/07/2017

DOI: 10.18677/Agrarian_Academy_2017a19

\begin{abstract}
RESUMO
A alface é uma hortaliça de grande importância mundial, seu consumo é o maior comparado com as outras folhosas. Para uma produção mais eficaz é necessário adequar a luminosidade, visto que este é um dos fatores que mais irá influenciar no crescimento. Dessa forma, o presente trabalho teve como propósito avaliar a emergência de variedades de plântulas de alface em função de diferentes níveis de luminosidade solar direta. O experimento foi conduzido no Centro de Ciências Agrárias e da Biodiversidade da Universidade Federal do Cariri, Crato-CE em delineamento inteiramente casualizado, em esquema fatorial 4x3 (quatro níveis de insolação e três variedades de alface), com cinco repetições. As bandejas foram dispostas em diferentes ambientes para captar sombra total; 1,5; 3; e 4,5 horas de incidência solar direta. $O$ tratamento de sombra total obteve os melhores resultados de IVE, \%Ei e \%Ef. A massa (g) e altura (cm), por sua vez, foi melhor representada pelo tratamento com três horas de luminosidade. A variedade Rafaela (americana) alcançou os melhores resultados para todas as variáveis analisadas, quando comparadas com as alfaces crespas, Cinderela e Mimosa.
\end{abstract}

PALAVRAS-CHAVE: incidência solar, Lactuca sativa, sombreamento

\section{EMERGENCE OF LETTUCE VARIETIES SUBMITTED OF DIRECT SOLAR LUMINOSITY}

\begin{abstract}
Lettuce is a vegetable of great importance worldwide, its consumption is the largest compared to other hardwoods. For a more efficient production it is necessary to adapt its luminosity, since this is one of the factors that will influence more in its growth. In this way the present work had as purpose to evaluate the emergence of lettuce seedlings varieties in function of different levels direct solar luminosity. The experiment was carried out in a completely randomized design, in a $4 \times 3$ factorial scheme (four levels of insolation and three varieties of lettuce), with five replications at the Centro de Ciências Agrárias e da Biodiversidade, Crato-CE. The trays were
\end{abstract}


arranged in different environments to capture total shade; 1,$5 ; 3$; and 4,5 hours of direct solar incidence. The total shade treatment obtained the best results IVE, \%Ei and \%Ef. The mass $(\mathrm{g})$ and height $(\mathrm{cm})$, in turn, was better represented by the treatment with 3 hours of luminosity. The Rafaela variety (american) achieved the best results for all analyzed variables when compared to the crisp lettuce, Cinderela and Mimosa.

KEYWORDS: solar incidence, lactuca sativa, shading

\section{INTRODUÇÃO}

A espécie (Lactuca sativa) pertencente à família Asteraceae é de grande relevância para a comercialização uma vez que esta é a hortaliça folhosa mais consumida no mundo. Além disso, possui elevada importância alimentar por ser fonte de vitaminas e sais minerais (SANTI et al., 2010).

Conforme dados do Programa Brasileiro de Modernização do Mercado Hortigranjeiros - PROHORT (2016), da Companhia Nacional de Abastecimento (Conab), a alface chegou a produzir cerca de duas mil toneladas na produção do ano de 2016 apenas pelo CEASA-CE da unidade Fortaleza. Um dos principais fatores que influenciam o crescimento dos vegetais é a luz, pois é a principal fonte de energia consumida pela fotossíntese. A quantidade e intensidade da luz podem modificar o metabolismo e o crescimento das plântulas (MARCOS FILHO, 2005).

Esse crescimento pode vir a refletir na habilidade de adaptação das espécies às condições de radiação do ambiente em que estão se desenvolvendo. $O$ grau de tolerância ou intolerância das espécies à baixa disponibilidade de luz pode ser compreendido com as características de crescimento (SCALON et al., 2012).

As principais cultivares de alface americana disponíveis no país possuem limitações em determinadas regiões e épocas de plantio (SALA \& COSTA, 2012). Na região Nordeste esta produção restringe-se a pequenas áreas, com a utilização de cultivares pouco adaptados às condições climáticas da região, o que contribui para o pendoamento precoce (QUEIROGA et al., 2001). De acordo com MORAES NETO et al. (2000) a capacidade das plantas crescerem rapidamente quando sombreadas é uma importante forma de adaptação da espécie, constituindo uma estratégia útil para resistir às condições de intensidade luminosa baixa. De forma geral, o grau de adaptação é definido por características genéticas da planta em interação com o ambiente (SCALON et al., 2012).

Sementes de cultivares diferentes germinam em faixas de temperatura distintas. A temperatura considerada ótima é aquela em que se alcança a mais alta percentagem de germinação em menor espaço de tempo (MAYER \& POLJAKOFFMAYBER, 1989). À vista disso, o conhecimento de genótipos capazes de germinar em temperaturas elevadas é de fundamental importância para o incentivo de projetos de melhoramento de alface, para regiões tropicais e subtropicais, com intuito a obter cultivares mais tolerantes e de qualidade superior com referência a germinação (CATÃO et al., 2014).

O mercado de produção do Brasil, por sua vez, consideram elementares os aspectos de produtividade, eficiência, lucratividade e sustentabilidade (SANTI et al., 2010). No que se refere a comercialização de mudas, o atraso na emergência das plântulas, eleva o custo de produção (LENHARD et al., 2013). Dessa forma, o presente trabalho teve como propósito avaliar a emergência de variedades de plântulas de Lactuca sativa (alface), em função de diferentes níveis de luminosidade. 


\section{MATERIAL E MÉTODOS}

O presente trabalho foi procedido no Centro de Ciências Agrárias e da Biodiversidade situado na Universidade Federal do Cariri, posto à altitude de $442 \mathrm{~m}$, com coordenadas geográficas de latitude sul de $7^{\circ} 14^{\prime} 3,4^{\prime \prime}$ e longitude oeste de $39^{\circ}$ 22' 7,6". De acordo com KÖEPPEN (1948), a classificação climática da região é Aw', apresentando, portanto, clima tropical com inverno seco. O experimento foi realizado no mês de janeiro de 2017, estando no período de estação chuvosa, esta ocorre entre os meses de novembro e abril.

O experimento foi conduzido com delineamento inteiramente casualizado, em esquema fatorial $4 \times 3$ (quatro níveis de sombreamento $x$ três variedades de alface), com cinco repetições. Os níveis de exposição ao sol foram: sombra total; 1,5; 3; e 4,5 horas de incidência solar. As variedades de alface (Lactuca sativa) utilizadas foram Cinderela, Mimosa e Rafaela (Americana).

A semeadura foi realizada em bandejas de poliestireno e o substrato composto por $50 \%$ de Argissolo Vermelho Amarelo, segundo a classificação de solos da FUNCEME (2012), e 50\% de esterco bovino. As sementes utilizadas são de uso comercial. Estas foram postas para germinar com profundidade de $1,0 \mathrm{~cm}$ e receberam irrigação diariamente.

Para alcançar os diferentes níveis de exposição solar, as bandejas foram dispostas em ambientes que captassem as diferentes horas de sol usadas para testar a emergência das plântulas. Já a bandeja com nível de sombreamento total foi posta na sombra, mas começou a receber 1,5 horas de incidência solar após o término da emergência, para poder analisar o desenvolvimento inicial das mudas, que necessariamente precisam de luz solar para o desenvolvimento.

Após o terceiro dia em que foram semeadas, as plântulas começaram a emergir. A partir daí foram iniciadas a coleta de dados para a análise das porcentagens de emergência inicial $(\% \mathrm{El})$, a porcentagem de emergência final (\%EF), a porcentagem de mortalidade (\%M), o índice de velocidade de emergência (IVE), a massa e a altura das plântulas.

Logo após sete dias houve estabilização no número de emergências, após essa data não foi contabilizada mais nenhuma emergência. Com 30 dias após a semeadura foi realizada a pesagem das plântulas com o auxílio de uma balança de precisão. Além disso, mediu-se as respectivas alturas com uma régua milimétrica.

Os resultados alcançados foram submetidos à análise de variância e, havendo diferenças significativas, as médias foram comparadas pelo teste de Tukey, a $5 \%$ de probabilidade para as variedades e à análise de regressão para determinar o melhor modelo significativo em função da luminosidade. O programa estatístico Sisvar 5.3 foi utilizado para realizar as análises.

\section{RESULTADOS E DISCUSSÃO}

$\mathrm{Na}$ tabela 1 verifica-se que os coeficientes de variação, conforme PIMENTEL GOMES (2009), foram altos (20 a 30) para todas as variáveis analisadas. Tais valores para pesquisas feitas em bandejas são considerados valores normais, 0 mesmo pode ter ocorrido em função do substrato utilizado ou influência do poder germinativo das sementes, o que também ocorreu com FLÔRES et al. (2016).

Observa-se na tabela 1, que não houve interação significativa entre o fator luminosidade e variedade. Entretanto, para todas as variáveis foi observado diferença significativa para os dois fatores em estudo. A variedade Rafaela (Americana) obteve melhores valores em todas as variáveis analisadas, sendo a 
Mimosa com menores resultados, mas sobressaindo-se somente na variável massa quando comparada com a Cinderela.

TABELA 1 Síntese da análise de variância e do teste de médias para a porcentagem de emergência inicial (\%El), a porcentagem de emergência final (\%EF), a porcentagem de mortalidade (\%M), o índice de velocidade de emergência (IVE), a massa das plantas (Massa) e a altura das plantas (Altura).

\begin{tabular}{|c|c|c|c|c|c|c|}
\hline \multirow[t]{2}{*}{ Fontes de Variação } & \multirow[t]{2}{*}{ G.L. } & \multicolumn{5}{|c|}{ Quadrados Médios } \\
\hline & & $\% \mathrm{El}$ & $\%$ EF & IVE & Massa & Altura \\
\hline Luminosidade (L) & 3 & $2489 * *$ & $2398 * \star$ & 147,9 ** & $2,99 * *$ & 1,516 * \\
\hline Variedade (V) & 2 & 7928 ** & 8268 ** & $127,1^{\star *}$ & 0,612 * & $6,844 * *$ \\
\hline Interação L*V & 6 & $143,6^{\mathrm{NS}}$ & $131,6^{\mathrm{NS}}$ & $2,08^{\mathrm{NS}}$ & $0,151^{\mathrm{NS}}$ & $0,270^{\mathrm{NS}}$ \\
\hline Resíduo & 48 & 146,2 & 145,5 & 3,33 & 0,141 & 0,397 \\
\hline CV (\%) & - & 22,80 & 22,36 & 26,40 & 24,31 & 22,93 \\
\hline \multirow[t]{2}{*}{ Fatores } & \multicolumn{6}{|c|}{ Teste de Médias de Tukey $(p<0,05)$} \\
\hline & & $\%$ El & $\% E F$ & IVE & Massa $(g)$ & Altura $(\mathrm{cm})$ \\
\hline \multicolumn{7}{|l|}{ Variedade } \\
\hline Cinderela (crespa) & & $54,0 \mathrm{~b}$ & $55,0 \mathrm{~b}$ & $6,87 \mathrm{~b}$ & $1,41 \mathrm{~b}$ & $2,14 b$ \\
\hline Mimosa (crespa) & & $32,7 \mathrm{c}$ & $33,1 \mathrm{c}$ & $4,42 \mathrm{c}$ & $1,49 a b$ & $3,17 \mathrm{a}$ \\
\hline Rafaela (americana) & & $72,5 \mathrm{a}$ & $73,8 \mathrm{a}$ & $9,47 \mathrm{a}$ & $1,75 \mathrm{a}$ & $3,23 \mathrm{a}$ \\
\hline \multicolumn{7}{|c|}{$\begin{array}{l}\text { Médias seguidas pela mesma letra minúscula na coluna, não diferem entre si pelo teste de Tukey a } 5 \% \text { de } \\
\text { probabilidade. }{ }^{* *} \text { : significativo }(P<0,01) ;{ }^{*} \text { : significativo }(P<0,05) \text {; NS: não significativo; CV\%: coeficiente de } \\
\text { variação. }\end{array}$} \\
\hline \multicolumn{7}{|c|}{$\begin{array}{l}\text { Em relação a porcentagem de emergência (Figura 1), o melhor modelo foi o } \\
\text { linear, verificando-se que com o aumento da luminosidade (h) os valores de } \\
\text { emergência inicial, emergência final e o índice de velocidade de emergência foram } \\
\text { decrescendo para as três variedades estudadas. } \\
\text { Os resultados alcançados diferiram do trabalho de BUFALO et al. (2012), } \\
\text { realizado em laboratório, tendo as sementes condicionadas em câmara de } \\
\text { conservação do tipo B.D.O, com temperatura controlável e luz artificial contínua. Os } \\
\text { autores concluíram que a presença de luz aumentou a germinação e reduziu o } \\
\text { tempo médio de germinação de mudas de alface. Estes resultados são importantes, } \\
\text { pois o efeito negativo da maior luminosidade neste artigo, foi em função da maior } \\
\text { incidência solar direta nas bandejas ocasionar elevação na temperatura, que } \\
\text { segundo NASCIMENTO et al. (2012), ao analisar a germinação de sementes de } \\
\text { alface em elevadas temperaturas, relataram que houve decréscimo na germinação e } \\
\text { vigor das sementes. }\end{array}$} \\
\hline
\end{tabular}




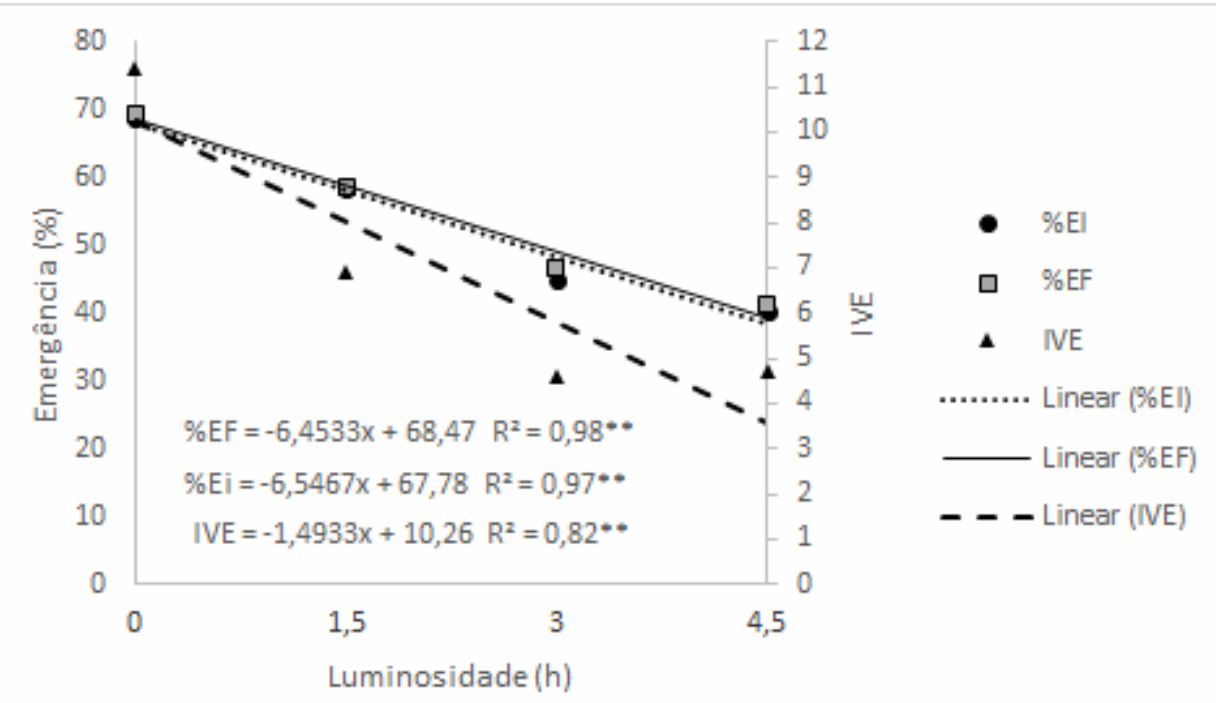

FIGURA 1. Porcentagem de emergência inicial, final e IVE em função do número de horas de luz solar direta, UFCA, Crato - CE, 2017.

Os dados para a massa e altura de plântulas estão apresentados na Figura 2. De acordo com o modelo de regressão, o melhor foi o polinomial de segunda ordem $(\mathrm{p}<0,01)$, podendo se notar que a altura é crescente até 3,2 horas de luminosidade, com um decréscimo para maiores períodos. Em relação à massa, o maior valor $(1,9$ g) foi observado para a exposição solar de 1,5 h.

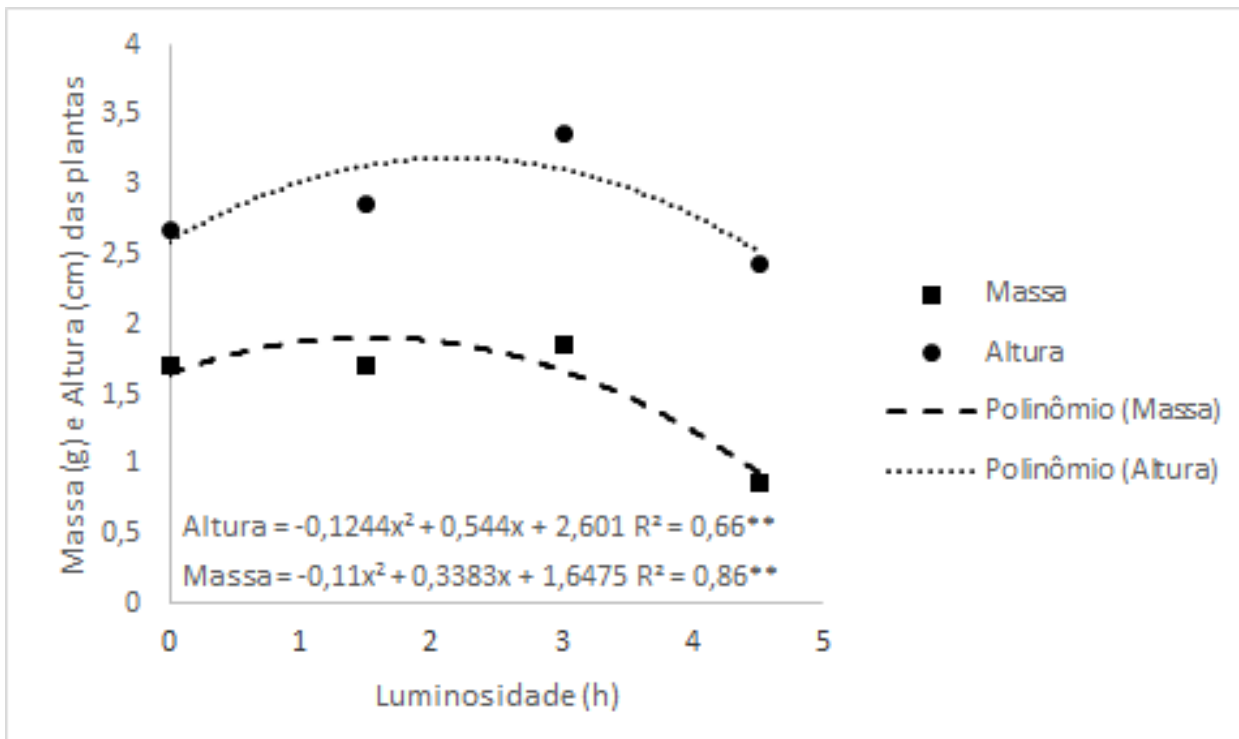

FIGURA 2 Altura e massa das plântulas de alface em função do número de horas de luz solar direta, UFCA, Crato - CE, 2017.

Resultados semelhantes foram encontrados por BEZERRA NETO et al. (2005), os quais ao reduzirem a luminosidade usando tela de cor branca obtiveram melhores valores de massa. Já para RICARDO et al. (2014), as variedades de alface apresentaram maiores médias de matéria fresca com o cultivo em campo aberto, 
com diferenças significativas para o uso de telas de sombreamento protegendo a cultura. AQUINO et al. (2014), observaram que para telas de sombreamento de $30 \%$ e $50 \%$ as médias de massa são inferiores quando comparadas a ambiente aberto e a tela termorrefletora de $30 \%$.

DALASTRA et al. (2016), verificaram que plantas cultivadas com $30 \%$ e $50 \%$ de sombreamento obtiveram maior altura em relação a luminosidade total. Isso deve-se ao fato de que plantas submetidas a baixa incidência solar desenvolve-se em busca da maior captação de luz, causando, muitas vezes, o estiolamento.

Desta forma, nota-se que a emergência das cultivares de alface estudadas apresentam melhor emergência quando as bandejas são colocadas na sombra (Figura 1), porém, após ser verificada a emergência, notou-se a necessidade de aumentar a exposição ao sol, por duas a três horas diárias, condições estas que apresentaram maior desenvolvimento da parte aérea (Figura 2).

\section{CONCLUSÕES}

De modo geral, através dos resultados obtidos, é possível perceber os impactos negativos da incidência solar direta na bandeja de mudas sobre a emergência de plântulas de alface das três variedades estudadas, sendo 0 horas de luminosidade o tratamento com melhores resultados de emergência e índice de velocidade de emergência.

Quanto a massa $(\mathrm{g})$ e altura $(\mathrm{cm})$, o uso de duas a três horas de incidência solar direta nas bandejas apresentou melhor desenvolvimento das mudas.

A variedade Rafaela (americana) obteve os melhores resultados para todas as variáveis testadas.

\section{REFERÊNCIAS}

AQUINO, C. R., SEABRA JUNIOR, S., CAMILI, E. C., DIAMANTE, M. S., PINTO, E. S. C. Produção e tolerância ao pendoamento de alface-romana em diferentes ambientes. Revista Ceres, Viçosa, v. 61, n.4, p. 558-566, 2014. Disponível em: <http://dx.doi.org/10.1590/0034-737X201461040016> DOI: 10.1590/0034737X201461040016

BEZERRA NETO, F.; ROCHA, R.C.C.; NEGREIROS, M.Z.; ROCHA, R.H.; QUEIROGA, R.C.F. Produtividade de alface em função de condições de sombreamento e temperatura e luminosidade elevadas. Horticultura Brasileira, Brasília, v.23, n.2, p.189-192, 2005. Disponível em: < http://dx.doi.org/10.1590/S0102-05362005000200005>. DOI: 10.1590/S010205362005000200005

BUfALO, J.; AMARO, A. C. E.; ARAÚJO, H. S.; CORSATO, J. M.; ONO, E. O.; FERREIRA, G.; RODRIGUES, J. D. Períodos de estratificação na germinação de sementes de alface (Lactuca sativa L.) sob diferentes condições de luz e temperatura. Semina: Ciências Agrárias, Londrina, v. 33, n. 3, p. 931-940, 2012. Disponível em: <http://dx.doi.org/10.5433/1679-0359.2012v33n3p931> DOI: 10.5433/1679-0359.2012v33n3p931

CATÃO, H. C. R. M., GOMES, L. A. A., DOS SANTOS, H. O., GUIMARÃES, R. M., FONSECA, P. H. F., \& CAIXETA, F. Aspectos fisiológicos e bioquímicos da germinação de sementes de alface em diferentes temperaturas. Pesquisa 
Agropecuária Brasileira, v. 49, n. 4, p. 316-322, 2014. Disponível em: <http://seer.sct.embrapa.br/index.php/pab/article/view/18743>.

DALASTRA, G. M.; HACHMANN, T. L.; ECHER, M. M.; GUIMARÃES, V. F.; FIAMETTI, M. S. Características produtivas de cultivares de alface mimosa, conduzida sob diferentes níveis de sombreamento, no inverno. Scientia Agraria Paranaensis, v. 15, n. 1, 2016. Disponível em: <http://dx.doi.org/10.18188/19831471/sap.v15n1p15-19> DOI: 10.18188/1983-1471/sap.v15n1p15-19

FLÔRES, J. A., SANTOS, L. A. C., SILVA, D. M. P., OLIVEIRA, I. A., PEREIRA, C. E. Desempenho agronômico de cultivares de alface em casa de vegetação no município de Humaitá, AM. Revista de Ciências Agroambietais, v.14, n.2, 2016. Disponível em: <http://periodicos.unemat.br/index.php/rcaa/article/view/1637>.

FUNCEME. Levantamento de reconhecimento da média intensidade dos solos da Mesorregião do Sul Cearense. Fundação Cearense de Meteorologia e Recursos Hídricos. Fortaleza, 2012.

KÖPPEN, W. 1948. Climatologia: con un estudio de los climas de la tierra. Fondo de Cultura Econômica. México.

LENHARD, N. R., PAIVA NETO, V. B., SCALON, S. P. Q., ALVARENGA, A. A. Crescimento de mudas de pau-ferro sob diferentes níveis de sombreamento. Pesquisa Agropecuária Tropical, v. 43, n. 2, p. 178-186, 2013. Disponível em: <http://dx.doi.org/10.1590/S1983-40632013000200012>～DOI: 10.1590/S198340632013000200012

MARCOS FILHO, J. Fisiologia de sementes de plantas cultivadas. Piracicaba: FEALQ, 2005.

MAYER, A.M., POLJAKOFF-MAYBER, A. The germination of seeds. Oxford: Pergamon, 1989. 270p.

MORAES NETO, S.P.; GONÇALVES, J.L. de M.; TAKAKI, M.; CENSI, S.; GONÇALVES, J.C. 2000. Crescimento de mudas de algumas espécies arbóreas que ocorrem na mata atlântica, em função do nível de luminosidade. Revista Árvore, Viçosa, v. 24, n. 1, p. 35-45, 2000.

NASCIMENTO, W.M.; CRODA, M.D.; LOPES, A.C.A. Produção de sementes, qualidade fisiológica e identificação de genótipos de alface termotolerantes. Revista Brasileira de Sementes, v.34, n. 3, p.510-517, 2012. Disponível em: <http://dx.doi.org/10.1590/S0101-31222012000300020> DOI: $10.1590 / \mathrm{S} 0101-31222012000300020$

PIMENTEL GOMES, F. Curso de estatística experimental. 15.ed. Piracicaba: FEALQ, 2009. 451p.

PROHORT. Programa Brasileiro de Modernização do Mercado Hortigranjeiros, 2016. Disponível em: < http://dw.prohort.conab.gov.br/pentaho/Prohort> 
QUEIROGA, R.C.F.; BEZERRA NETO, F.; NEGREIROS, M.Z.; OLIVEIRA, A.P.; AZEVEDO, C.M.S.B. Produção de alface em função de cultivares e tipos de tela de sombreamento nas condições de Mossoró. Horticultura Brasileira, v.19, n.3, p.324, 2001. Disponível em: <http://dx.doi.org/10.1590/S0102-05362001000300006> DOI: $10.1590 /$ S0102-05362001000300006

RICARDO, A. S., VARGAS, P. F.; FERRARI, S.; PAVARINI, G. M. P. Telas de sombreamento no desempenho de cultivares de alface. Nucleus, v.11, n.2, out, 2014. Disponível em: <http://dx.doi.org/10.3738/1982.2278.1375> DOI: $10.3738 / 1982.2278 .1375$

SALA F. C; COSTA C. P. Retrospectiva e tendência da alfacicultura brasileira. Horticultura Brasileira. v. 30, n. 2, p. 187-194, 2012. Disponível em: <http://dx.doi.org/10.1590/S0102-05362012000200002>. DOI: 10.1590/S010205362012000200002

SANTI A; CARVALHO MAC; CAMPOS OR; SILVA AF; ALMEIDA JL; MONTEIRO S. Ação de material orgânico sobre a produção e características comerciais de cultivares de alface. Horticultura Brasileira, v. 28, p.87 - 90, 2010. Disponível em: <http://dx.doi.org/10.1590/S0102-05362010000100016> DOI: 10.1590/S010205362010000100016

SCALON, S. P. Q.; SCALON FILHO, H.; MASETTO, T. S. Aspectos da germinação e desenvolvimento inicial de plântulas de aroeira. Cerne, v.18, n.4, p.533-539, 2012. Disponível em: <http://dx.doi.org/10.1590/S0104-77602012000400002>. DOI: $10.1590 /$ S0104-77602012000400002 